\title{
Patients' experiential knowledge and expertise in health care: A hybrid concept analysis
}

\author{
Eva Marie Castro ${ }^{1}$ Tine Van Regenmortel ${ }^{2,3} \cdot$ Walter Sermeus $^{4}$. \\ Kris Vanhaecht ${ }^{4,5}$
}

(C) Springer Nature Limited 2018

\begin{abstract}
Although the concept of experiential expertise is relatively new in modern health care services, policy, and research, it has profound implications for improving participation in healthcare. The absence of theoretical and conceptual clarity has led to poor understanding and miscommunication among researchers, health practitioners, and policy makers. The aim of this article is to present a concept analysis of experiential expertise and to explain its defining characteristics, applicability, and significance. A combination of Rodger's evolutionary method combined with Schwartz-Barcott and Kim's hybrid model was selected as a method for the analysis of the experiential expertise concept. This method combines theoretical (24 definitions) with empirical data analysis (17 interviews). Antecedents, attributes, and consequences are determined. A comprehensive definition is provided, and the interrelatedness between experiential expertise and related concepts was mapped. Experiential expertise is a complex process exceeding the boundaries of individual experiences. Its availability cannot be taken for granted. Using experiential expertise in health care can facilitate patient empowerment leading to improved quality of life and health care. The present study offers clarity by proposing a conceptual model that can assist researchers, policy makers, and health care professionals in facilitating implementations in practice.
\end{abstract}

Eva Marie Castro

evamarie.castro@soc.kuleuven.be

1 Faculty of Social Sciences, KU Leuven, 3000 Louvain, Belgium

2 Faculty of Social Sciences - HIVA, University of Leuven, Louvain, Belgium

3 Tilburg School of Social and Behavioral Sciences, Tilburg University, Tranzo, Tilburg, The Netherlands

4 Department of Public Health \& Primary Care, Leuven Institute for Healthcare Policy, University of Leuven, Louvain, Belgium

5 Department of Quality Management, University Hospitals Leuven, Louvain, Belgium 
Keywords Experiential knowledge $\cdot$ Experiential expertise $\cdot$ Co-production · Concept analysis

\section{Introduction}

Co-production is increasingly being applied in the delivery and evaluation of services in modern health care (Batalden et al. 2017). It refers to the active input by people who use(d) services together with people who provide services. Co-production in health care is promoted by supranational organizations such as the World Health Organization and is situated in a shift from paternalistic to deliberative and empowering models (World Health Organization 2015). At the backdrop of the declining status of professional expertise and the democratization of knowledge, sociologists report a shift in the terminology to refer to the patients perspective. Since the 1990s, sociologists do no longer use the terms 'lay health beliefs,' instead they use the term 'lay knowledge and expertise' (Blume 2017). This combination of reasons implied that patients, who first were considered as passive subjects, now have come to be seen as "experts" with knowledge about their own bodies, symptoms, and life situations.

Experts by experience are potential co-producers of care. As long-term service users they do not only have experienced a particular disease of disability, they also gained knowledge about it and about the health care services they use. Additionally, they possess the appropriate competencies (e.g., attitudes and skills) to bring their knowledge into action. Although not the same, some authors refer to them as 'expert patients,' 'trained patients,' or 'peer counselors.'

The need for a concept analysis in the context of medical health care arises from both literature and practice. Experts by experience can co-produce care at the level of direct care (micro level) as well as at the level of care organization (meso level) and policy (macro) (Nickel et al. 2016). With respect to direct care, experts by experience can provide mental, social, and practical care. With respect to care organization and policy, experts by experience can co-evaluate care. The literature demonstrates various examples of successful co-production initiatives (Crawford et al. 2002; Mockford 2012; Sharma et al. 2017). Nevertheless, examples exist where professionals do not seem to value patients' contributions (Solbjør and Steinsbekk 2011). An often-cited criticism is that patients merely reflect from their individual viewpoint and experiences and that they lack the knowledge about the care system in which they participate. Therefore, the effect of their insights on the daily work of healthcare professionals is reported to be rather limited (Solbjør and Steinsbekk 2011). Practical experiences and observations from other domains show that the involvement of experts by experience has the potential to counter this criticism since experts by experience seem to possess the essential competencies to contribute to the micro, meso, and macro level as well (Boivin 2014).

Sociologist Borkman (1976) was the first to theoretically clarify the concepts 'experiential knowledge' and 'experiential expertise.' She defined experiential knowledge as "the truth learned from personal experience with a phenomenon rather than truth acquired by discursive reasoning, observation, or reflection on information provided by 
others." It refers to wisdom and know-how gained from a personal experience with a phenomenon such as a disease or disability. Experiential expertise, the second concept, was defined as "a competence or skill in handling or resolving a problem through the use of one's own experience"(Borkman 1976). The most important difference between both concepts is that everyone with the same problem may have experiential knowledge, but the degree in which one has integrated the information and is competent to share the knowledge to others, varies. Borkman's definitions form a firm basis but are related to self-help groups and date from 40 years ago.

While a body of recent literature highlights renewed acknowledgement (Tambuyzer et al. 2014), experiential expertise seems to be a concept which is poorly understood in the current health care context (Mclaughlin 2009; Scourfield 2010; Miaskiewicz and Kozar 2011). In literature and practice as well, different understandings by different stakeholders are reported. This is due to the complex and multifaceted nature of the concept experiential expertise. The concept has been used in diverse sectors (e.g., mental health, social work) through multiple modes of interaction (e.g., one to one, groups), in diverse settings (e.g., hospital, training), and domains (e.g., social work, mental health, addiction treatment). It incorporates a variety of roles (e.g., mediator, advocate, change agent) and activities with varying degrees of involvement and structure (e.g., formalized versus informal, paid versus unpaid).

Experiential expertise is most developed in mental health services (Repper and Carter 2011), and social work (Casman et al. 2010; Roets et al. 2012). Often in these domains, experts by experience are even employed, or competency and function profiles are developed by policy makers (Vandenbempt and Demeyer 2003; van Bakel 2013). This is in contrast to the area of medical health care where the term experiential expertise is often diminished in impact by making it interchangeable with the term "lay expertise," "patient expertise," or even "peer support" (Civan 2009; Thompson et al. 2012). The aim of this article is to illuminate the core aspects of experiential expertise. By combining theoretical and empirical data from medical, mental, and social care, our study provides a comprehensive and operational definition. We aim to contribute to the development of theory and practice in the Netherlands and Belgium, but also to the international literature regarding co-production of care.

This study is part of a larger research project which aimed to develop and test a method to structurally involve experts by experience in hospital services. Therefore, 14 experts by experience were employed in three services of a large Belgian hospital during almost 10 months. To conduct this study properly, we first had to clarify the concept of experiential expertise. We then explore one case study to illustrate the concept in practice. A full description and evaluation of the case studies will be described in another paper. 


\section{Methods}

Concept analysis is widely viewed as a process that enhances theory development and empirical research (Goertz 2006). After a comparative study of different approaches, a combination of Rodgers' evolutionary method with Schwartz-Barcott and Kim's hybrid concept analysis seemed the most appropriate method (Rodgers and Knafl 2000). This hybrid model aims to illuminate the essential aspects of concepts by combining inductive and deductive approaches. The strength of the method lies in the combination of data collection from theory and practice. As a result, it fits perfectly with the objective of this paper: to develop a comprehensive and operational definition, which promotes both theory development and empirical research. The hybrid method consists of three phases: (1) the theory phase, (2) the fieldwork phase, and (3) the analysis phase. The initial theoretical phase requires comparison of theoretical definitions from literature, to develop a tentative working definition. The second phase, which is empirical, builds on the working definition and aims to thoroughly identify the defining characteristics. The final analytical phase starts from the findings of the first two phases and includes comparisons, contrasts, and adaptations to clarify and refine the concept.

\section{Phase 1: theoretical phase}

\section{Search strategy concept analysis}

The strategy included a protocol-driven search, combined with a secondary search (snowballing), following the recommendations of Greenhalgh (2005) (see Fig. 1). We included peer-reviewed papers in international (English) medical, sociological, psychological, and nursing literature. Four databases were searched (Pubmed, Web of Science, Embase, and JSTOR) with the following keywords entered: 'expertise by experience,' 'experiential expertise' with and without the search term 'definition.' Furthermore, Dutch journals and books were searched manually. Finally, we also searched gray, mostly unpublished, literature, policy and legislation documents, and the search engine Google. Using the snowball method, we screened reference lists and citations. Original research articles as well as theoretical and conceptual articles were consulted. We did not limit our search by publication date.

\section{Eligibility criteria}

Publications with a definition of expertise by experience were included in the literature study. First, titles and abstracts were screened to exclude irrelevant records. Second, full-text articles were retrieved for all selected records. Third, full texts were screened to establish whether they fulfilled inclusion criteria. Articles that showed how these concepts were understood, described, and operationalized were included. We only included articles derived from the areas of social work (poverty and social exclusion), mental health care, and medical health care as the concept is most frequently used and developed in the first two areas. As the aim was to identify 


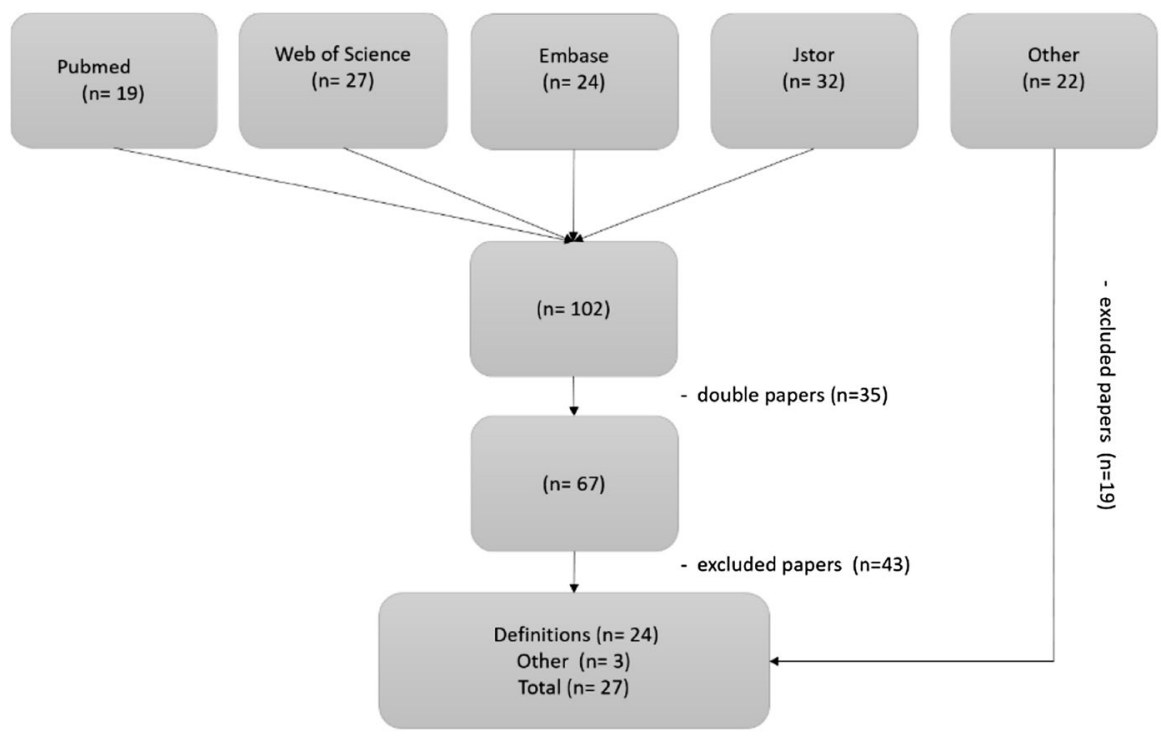

Fig. 1 An overview of the search strategy (p. 7)

a broad range of conceptual definitions used in the literature, no further assessment of the validity or quality of the full text was conducted. This selection process continued until a saturation point was reached in terms of breadth of understanding and descriptions. When no new information emerged after three papers, the search was ceased. Finally, all definitions were screened by two peers from the same research unit, who evaluated their appropriateness. As a result, 24 definitions of "experts by experience" were included 12 in (medical) health care, 9 in mental health care, 3 in social work (see "Appendix 1"). Three other papers (without a definition but with a useful description of the concept) were included.

\section{Content analysis}

We used content analysis, based on an inventory of several definitions of the concept. The clarification process incorporated aspects of concept analysis strategies proposed by Rodgers and included criticism on existing definitions and identification of the antecedents, attributes, and consequences (Rodgers and Knafl 2000). Each definition was divided into meaningful units that were subsequently coded. A coding sheet was developed in an iterative process. The sheet was continuously extended if new codes emerged during the analysis of new definitions. It was then revised by two other members of the same research unit. Finally, the codes were grouped into meaningful clusters (e.g., experience with a phenomenon). 


\section{Phase 2: empirical phase}

\section{Interviews with key informants}

Schwartz-Barcott and Kim (2000) consider fieldwork as an essential element in concept development. In hybrid concept development, qualitative data are used to develop insight into the nature of the concept (Rodgers and Knafl 2000). In an attempt to maximize response diversity, we recruited a purposive sample consisting of experts by experience and professionals in social work, mental, and medical health care in Belgium and the Netherlands. In social work and mental health, caregivers are more aware of 'expertise by experience.' Purposive sampling is a common approach in qualitative research. It allows the selection of participants whose experiences permit an understanding of the phenomena in question (Polit and Beck 2012). The aim was to collect the key-informants' views about the meaning of experiential expertise. Experts by experience, health care workers, and researchers were contacted through self-help organizations and the researchers' network. Inclusion criteria were age 18 or over and personal experience with the enablement of experts by experience. In total, 17 explorative interviews took place face-to-face. The transcripts of 11 experts by experience, 4 professionals, and 2 researchers were analyzed. One respondent was both a professional and a researcher (see "Appendix 2" for the respondents' characteristics).

\section{Analytical phase}

The analytical reflection involved combining definitions derived from the first two phases, resulting in possible changes to the definition and refinement of the concept. The results of the qualitative data were tested against all theoretical data. Similarities and differences between the two sets of findings were extracted and noted.

To improve the readability, we described the first ("theoretical") and second ("empirical") phase together in the following section. The third ("analytical") phase is described in "Analytical reflection."

\section{Results}

\section{Antecedents (based on theoretical and empirical phase)}

A common thread in the definitions of experiential expertise is that its development starts with experiencing a phenomenon, such as a chronic disease or disability on a daily basis (Van Erp et al. no date; Borkman 1976; Rietbergen et al. 1998; van Haaster and Koster-Dreese 2005; Boevink 2006, 2012; Karbouniaris and Brettschneider 2008; Timmer and Plooy 2009; Casman et al. 2010; Knooren 2010; Van Regenmortel 2011; Bovenberg et al. 2011; van Haaster 2013; Verbrugge and Embregts 2013). These experiences relate to the patient's body, care, recovery, and his/her social environment. (Caron-Flinterman et al. 2005; van Haaster 2013). For 
example, when living daily with rheumatism, patients have to deal with pain in their body, they often have to rely on professionals or informal care, they have to take care for themselves in order to prevent worsening and they need to combine the care for their condition with other things such as being a parent, an employee, or a partner. All these experiences are concrete and they strongly depend on a patient's personal situation and social profile. As such, a young female student will experience rheumatism in another way than elderly widower.

Another crucial dimension is experiential knowledge (Van Erp et al. no date; Borkman 1976; van Haaster and Koster-Dreese 2005; Boevink 2006, 2012; Plooy 2007; Timmer and Plooy 2009; Van Regenmortel 2009; Casman et al. 2010; van Haaster 2013). A person acquires experiential knowledge by analyzing and reflecting repeatedly about one's own experiences and reading for example patient stories through blogs or online communities and medical literature (van Haaster and Koster-Dreese 2005; Karbouniaris and Brettschneider 2008; Timmer and Plooy 2009; Van Regenmortel 2009; Posthouwer and Timmer 2013; van Haaster 2013). By comparison this kind of knowledge continuously develops through observation and imitation. The empirical data confirm this:

"In addition to the experience of the disease, you have to build up knowledge and gain insights into your experience. You also have to meet others so you can observe similar experiences and afterwards you can think "ah, it's the same for them". In that way, you create insights into the experiences of others, which results in recognition." (expert by experience)

In the literature, terms such as "embodied knowledge" or "knowledge from within" are also used to describe experiential knowledge. Experiential knowledge is characterized by an unconscious and automatic component, as it is learned through daily experiences. It is implicit and thus difficult to describe (Lam 2000; Thompson et al. 2012; Burda et al. 2016; Utschakowski 2017). Experiential knowledge is therefore often compared to cycling: it is knowledge that one can put into practice, but it is difficult to describe and explain to someone else.

In the literature, a distinction is made between personal and collective experiential knowledge. Whereas personal knowledge is reserved for oneself, collective knowledge is the result of sharing the individual knowledge with others with similar experiences, for example, in patient organizations (Burda et al. 2012, 2016; Verbrugge and Embregts 2013). Doing so creates a sense of familiarity and recognition and leads to a collective body of knowledge (van Haaster 2013). By listening to others with the same condition, the boundaries of individual experience are exceeded and collective experiential knowledge is acquired (Caron-Flinterman et al. 2005; Korevaar and Droës 2011; Boevink 2012). The broadening of individual experiential knowledge as a prerequisite for experiential expertise is confirmed by the empirical data of this study. Furthermore, respondents stated that this goes hand in hand with the processing or acceptance of a patient's disease or disability.

"Processing and extending the experience is very important. You have to focus on your own story but also on that of someone else. My experience 
can be very different from that of the other. An expert by experience must

be aware that such a width exists." (professional)

Having the appropriate competencies to articulate experiential knowledge is another crucial antecedent (Borkman 1976; Karbouniaris and Brettschneider 2008; Casman et al. 2010; Posthouwer and Timmer 2013; van Haaster 2013; Erp et al. 2015). Through specific training or learning path (e.g., learning from practice) one obtains the appropriate attitudes (e.g., open attitude towards others), skills (e.g., active listening), and knowledge (e.g., regulations concerning doctor-patient confidentiality) to put his/her experiential knowledge into action. The necessary competencies depend and differ on the areas where the experiential expertise will be used.

The importance of training to develop experiential knowledge into experiential expertise is also acknowledged by empirical data. The purpose of training is to deploy experiential knowledge in an expert and ethical manner and to give future experts by experience sufficient self-confidence when they become an actor in a health care context which is merely dominated by medical technical knowledge. However, respondents highlight the importance to carefully monitor the potentially excessive level of training as that could threaten the possible advantages of experiential expertise. The majority states that the authenticity of the experiential expertise must be preserved and that the expert by experience should not evolve into a pseudo-professional. Therefore, regular interaction between peers, supervision, and retraining but also with team members or patient associations are crucial.

\section{Attributes (based on theoretical and empirical phase)}

Experiential expertise is based on a daily-lived experience with a particular disease or disability. It includes for example experience in dealing with one's injured body (e.g., an amputation) and the associated difficulties (e.g., climbing stairs, practicing sports), experience in dealing with health care providers and health care institutions (e.g., several hospital admissions or doctor visits to test a prosthesis), and experiences in dealing with social comments and stigma (e.g., people staring). As such, this broad-lived experience is a source for problem solving and support (e.g., learning how to climb stairs, dealing with staring people). Subsequently, distinctive characteristics of experiential expertise are pragmatic, oriented to 'here-and-now' action and holistic. A person with an amputation has to translate the technical-theoretical explanation of a physiotherapist into practice, has to deal with wounds caused by the prosthesis, and has to integrate its disability into his/her daily life (e.g., going to work). One of the respondents stated that this type of expertise is subjective, a dimension often filtered out in other kinds of knowledge:

The knowledge domain of experiential expertise differs from regular professional knowledge. Something that objectively seems a "mosquito" can be subjectively be experienced as an "elephant" throughout your life. Something that is scientifically a small negligible detail within treatment can be of great importance in daily life. (expert by experience) 
Experiential expertise distinguishes itself from other similar concepts (e.g., lay knowledge) by the specific expertise in bringing the experiential knowledge into action. It is characterized by experience-based expertise, which is complementary to expertise based on medical, scientific, technical, and theoretical knowledge.

This complementarity between experiential and professional expertise was repeatedly stressed by the respondents of the empirical part of this study. Professionals often seem to approach patients from a purely theoretical or medical point of view. With their clinical medical knowledge, they try to improve patients' physical health. For dealing with very practical issues, for example, they often have too little expertise (e.g., swimming with a stoma). Experts by experience, with their experiential knowledge, have the expertise to support people living with a chronic disease or disability in various areas of daily life. Their first-hand experience with a certain condition complements professional care.

In contrast to experiential knowledge, which is mostly implicit, experiential expertise is explicit and transferable to others (e.g., peers, professionals) and to several situations (e.g., evaluating care organizations, informing other patients) and contexts (e.g., health care institutions) (Casman et al. 2010; Burda et al. 2012, 2016). The mode of application is highly variable (individual versus group, face-toface versus online, etc.).

Experiential expertise presupposes the transfer of experiential knowledge, in a structured and orderly manner, at four levels: micro, meso, macro, and meta (Tambuyzer et al. 2014). At the micro level or the level of direct care, experiential expertise is used to offer peers emotional, social, and practical support through multiple modes of interaction (e.g., individual one-to-one sessions, group sessions). At the meso level, the level of the organization, experiential expertise is used to improve health care quality through involvement in service development or evaluation through a variety of participation methods (Tritter 2009; Roets et al. 2012). At the macro level, the expertise can be used to ensure that the health care system and policy is oriented and responsive to the patient's perspective. Finally, the experiential expertise can be used at the meta level (e.g., research and education), which spans all the other levels.

\section{Consequences (based on the theoretical and empirical phase)}

The scarce literature regarding 'effects' of the use of experiential expertise in health care settings suggests an enhancement of societal integration, societal participation, increased mental health confidence, fewer self-reported symptoms, lower level of need for care, reduced risk of institutional residence (Burda et al. 2012, 2016; Boevink et al. 2016), and patient empowerment (Casman et al. 2010; Korevaar and Droës 2011; Boevink 2012). Ultimately, this leads to a better quality of life (Tambuyzer et al. 2014).

The empirical data suggest that the enablement of experts by experience results in effects with respect to the experts themselves. They report mutually empowering relationships between the giver and receiver as both benefit from the interaction. 
Respondents stated that having a valued role and an opportunity to contribute to care for patients with a similar condition can have a powerful effect on their identity.

A second consequence is related to the professionals' context. The use of experiential expertise will lead to improved service quality. Experts by experience look at the services through different eyes (Korevaar and Droës 2011) which results in improvements in accessibility (Casman et al. 2010) and patient-centeredness. The empirical data suggest that valorization of experiential expertise in medical health care can assist in creating a culture change to ensure that patients and health care professionals co-produce care to meet the patients' needs. In the fields of mental health care (Netherlands and Belgium) and social care (Belgium), experts by experience already contributed to a cultural shift from a supply-driven to a demand-driven approach. However, the positive use of experiential expertise depends on the "professional' stakeholders, who either agree to work with them and acknowledge their expertise, or don't. A frequently cited obstacle impeding successful collaboration is the lack of interaction with the head of a specific hospital department, who is often a doctor or head nurse. A recent study of Malfait et al. (2017) showed that especially younger health care staff have difficulties in accepting 'a new collaborative role.' Overall, the literature points out that an open attitude is a prerequisite for successful collaboration with experts by experience (Tambuyzer et al. 2014; Castro et al. 2016, 2018).

\section{Analytical reflection (based on the analytical phase)}

By comparing the conceptualization of expertise by experience as reported in literature to the one that is described by key informants in the empirical part of this study, no substantial discrepancies were noted between the two data sets. However, one aspect in the analysis of the empirical data is noteworthy. Respondents consider training (provided by both the staff of the self-help clearinghouse and the medical professionals) important, but the underlying reason for this differs. Professionals point out the importance of 'competent patients,' as a kind of 'quality assurance' for the health care service, the professionals, and the patients with whom they come into contact. This in contrast to experts by experience who consider training important in order to participate in an ethical and authentic way, to build self-confidence, and to be able to deal with difficult and delicate situations.

In conclusion, personal experience, individual and collective experiential knowledge, and a wide range of competences, optionally enhanced by training, seem to be crucial antecedents in both data sets. Analyzing, reflecting, consulting various sources and sharing knowledge together will enhance the development of experiential expertise. Figure 2 presents a summarizing overview of antecedents, attributes, and consequences of expertise by experience. This kind of expertise is complementary to professional knowledge, draws on expertise regarding how to cope with disabilities and situations, and is transferable to others in several situations and contexts. It thus leads to co-producing care, resulting in 'patient empowerment,' 'improved quality of care,' and in the long term to 'better quality of life.' 


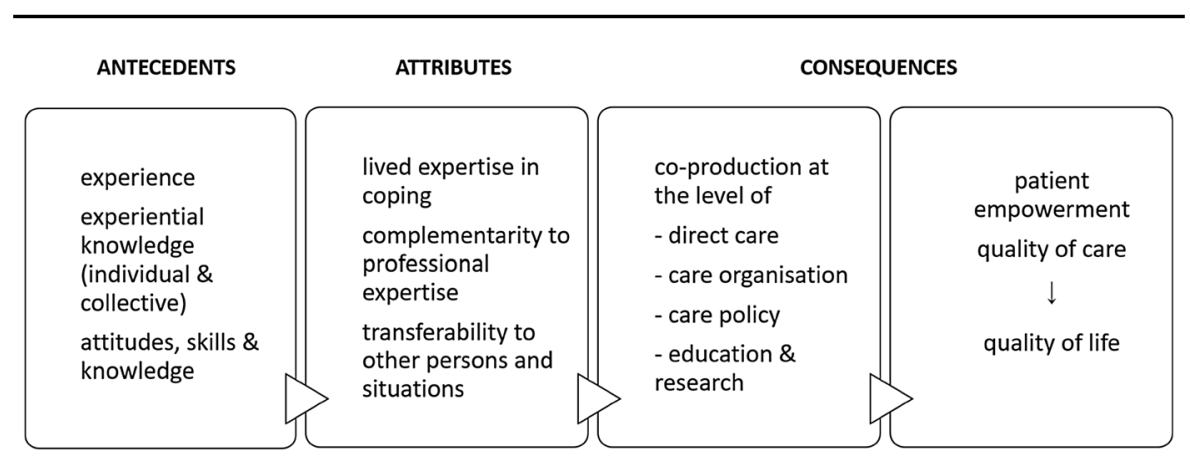

Fig. 2 Integrated overview of the antecedents, attributes, and consequences of the concept (p. 17)

As a result of a thorough literature search and empirical data analysis, a comprehensive definition of experiential expertise was developed. We established a generic and a specific part. The generic part is based on similar aspects derived from the data of mental health care, social care, and medical health care. The specific part particularly applies to medical health care and is indicated in italics.

Expertise by experience is the expertise built on one's shared, widened, and processed experiences of (1) coping with one's own body and condition, (2) dealing with health care providers and their organizations, (3) handling social reactions, and (4) relating to peers aiming to expertly transfer this experiences at different levels in order to co-produce 'services' and to facilitate empowerment, quality of life, and quality of care.

\section{Understanding experiential expertise through an illustrative case}

A case in the Dutch-speaking part of Belgium, drawn from the authors' research, illustrates key characteristics of the concept. The case concerns "the experts by experience intervention," which involved 14 experts by experience in the delivery and evaluation of three hospital services. During a pilot study (October 2016-June 2017), the intervention was tested, refined, and evaluated. Fourteen experts by experience were systematically employed: six at a rehabilitation center, four at a renal center, and four at a dermatology consultation.

A researcher recruited the patients with experience in amputation, spinal cord injury, renal disease, and atopic eczema through patient associations and contact persons of the hospital wards. A three-person jury selected them on the basis of a motivation letter and interview. They mainly focused on the collective experience knowledge and an "open" attitude, as these competencies are difficult to train. The jury consisted of a staff member of the Flemish Patient Platform (an umbrella organization that defends the interests of chronic patients in several commissions and policy bodies at the macro level), the coordinator of the Flemish self-help clearinghouse, and a member of the board of a patient association regarding breast cancer who was an expert by experience herself.

All experts by experience participated in a co-design trajectory, where they collaborated with other patients and health care professionals to design the experts by 
experience intervention (Castro et al. 2017). During this co-design trajectory, the group discussed several topics, among others: goals of their engagement, tasks and roles, preconditions for successful integration, practical organization, and the desired training. The result was a training course, mainly to enhance skills and knowledge. The training included four aspects: a basic course to enhance social skills (conversation and listening techniques, communication with caregivers, dealing with difficult and delicate situations), a pathology-specific course (medical background information), an introduction to volunteer service and hospital organization (hygiene, safety, discretion, and privacy rules), and an introduction to the specific hospital departments. Staff members of the self-help clearing house together with the hospital departments organized the training. In addition, staff members of a selfhelp groups' support center provided extensive support to the experts by experience though regular individual coaching sessions, monthly intervision (i.e., group sessions where experiences are exchanged) and supervision in group and bimonthly meetings with the health care professionals of the hospital wards. This extensive support was needed so that the experts by experience could transfer their experiential knowledge to patients and professionals as well.

Experts by experience conducted two tasks. They offered patients complementary (mental, social, and practical) support through several modes of delivery (tailored to the concerning hospital ward) such as individual face-to-face sessions, group faceto-face sessions (e.g., during therapy and exercise sessions, workshops), e-mail, or an online community. As such, they put their expertise in coping with their disease or disability into practice. The other task of the experts by experience was to offer professionals a continuously evaluation of the organization and the delivery of care, based on issues reported to them. As stated in the introduction, this case will be described in another paper.

\section{Discussion and conclusion}

\section{Discussion}

The unraveling of the characteristics of the concept of experiential expertise contributes to the theory development, empirical research, and the valorization of the informal knowledge of patients with chronic conditions. Currently, medical and scientific knowledge dominates health care settings. Expertise based on experience is often neglected because it is considered to be subjective and individualistic and therefore not evidence-based nor scientific. Professional knowledge alone seldom considers 'life with a condition or disease.' Furthermore, experiential knowledge can be differentiated from professional knowledge as mostly implicit, pragmatic, holistic, and oriented to 'here-and now' action. Professional knowledge is mostly explicit, theoretical or scientific, long-term oriented and segmented (Borkman 1976; Lam 2000), and revolves primarily around embrained knowledge (i.e., 'high-level knowledge' which depends on conceptual skills and cognitive abilities). By combining both forms ("co-producing"), the gap between patient knowledge and professional knowledge can be bridged. This may lead to a new and more balanced distribution 
of knowledge which better meets the needs of patients with long-term diseases or disabilities.

Not only differences but also similarities between experiential and professional expertise can be outlined. The development of the expertise itself runs through the same stages. Dreyfus' Model of Skill Acquisition explains the mental processing of becoming an expert (Dreyfus and Dreyfus 1980). The evolution from a 'novice' to an 'expert' is characterized by a shift from rather abstract towards more 'intuitive' and 'holistic' problem-solving actions. The more experience someone has, the more of an expert he or she becomes in problem solving. However, not every patient will evolve into an expert by experience, nor can every nurse become an expert according to Benner (Frampton et al. 2008). She states that many nurses often remain in the third stage, which stands for 'a competent nurse.'

The results of this concept analysis reveal that experiential expertise differs from other concepts such as peer support which is often used interchangeably with experiential expertise. The main differences are situated in the following three areas. First, experiential expertise is a multilevel concept because experiential expertise is usable at the level of direct care (micro level), care organization (meso level), care policy (macro), and research and education (meta). This is in contrast to peer support, which only targets the level of direct care. Second, it takes a number of requirements to develop experiential expertise. A first prerequisite is the availability of collective experiential knowledge (e.g., by being a member of a patient association) as it is important to exceed the boundaries of one's own experiences. A second prerequisite is the competency to transfer this collective experiential knowledge to others. This also leads to a crucial difference with the concept of 'peer support'(Mead et al. 2001; Dennis 2003). Peers share the same experiences and have experiential knowledge but in contrast to experts by experience, they do not automatically have collective experiential knowledge and experiential expertise. Peer support is 'limited' (no value judgement intended) to supporting peers (emotionally, by appraisals and with information) while experts by experience can have multiple roles at the micro, meso, macro, and meta level ranging from supporting (and defending) peers (their interests) to involvement in improvement trajectories (Tambuyzer et al. 2014). Third, experiential expertise can be used for the benefit of patients (e.g., informing and supporting) and professionals (evaluating care organization), where peer support mainly focuses on supporting peers. All these characteristics imply that experiential expertise is a broader concept than peer support.

In "Consequences" of the paper, we propose a comprehensive definition that captures the essential dimensions of experiential expertise in terms of antecedents, attributes, and consequences. To our knowledge, no recent studies have thoroughly analyzed this concept in health care. Our concept analysis addresses an important gap in the literature as formulated by Scourfield (2010) and Mclaughlin (2009). Despite its upcoming popularity, the concept has never been analyzed before. Because the domains of mental health care and social work have more experience and knowledge concerning experiential expertise, we included literature and empirical data from these domains resulting in a comprehensive definition and framework. 
This framework has the potential to facilitate co-production initiatives by offering guidance in the selection process and further implementation in practice. By using a hybrid concept analysis, we provided insight into how the concept is expressed in theory and practice. This enabled us to validate, broaden, and deepen the data that were identified in the theoretical phase resulting in a comprehensive definition and framework that is representative for both theoretical and empirical perspectives. However, the authors are aware that the theoretical framework is an artificial simplification of a complex concept.

\section{Study limitations}

We did not conduct a systematic evaluation of the quality of research articles included as our aim was to consider all relevant research. Furthermore, we interviewed fewer respondents in the social work domain as we felt that saturation was reached and no new information emerged from the data.

\section{Further research}

The experiential expertise of relatives has been excluded in our study but should be considered in further research. Abel and Browner (1998) differentiate between the knowledge of persons with personal experiences of bodily experiences ("embodied knowledge") and the knowledge of relatives whose knowledge derives from close emotional ties ("empathetic knowledge") (Blume 2017). Finally, the application of the concept raises a number of questions: "Who gives these individuals authority to speak as experts by experience?" "Who will organize the training for experts by experience?" What kind of training do they need? What kind of issues do experiential experts face in the medical community? In order to answers these kinds of questions, there is a need for the development of more interventions that involve experts by experience in the medical health care.

\section{Conclusion}

This study systematically analyzes the concept of experiential expertise by describing its antecedents (experience with a chronic condition, experiential knowledge, competencies), attributes (experience and knowledge in coping with disabilities and situations, complementarity to professionals expertise, transferability to other persons, situations, and contexts), and consequences (patient empowerment and quality of care) in health care. Doing so, the study aims to contribute to theory development, to facilitate empirical research, and to contribute to the valorization of the knowledge of patients as an essential complement to the knowledge of professionals. As such, the concept of experiential expertise also fulfills a "symbolic" function as it can be understood as a self-conscious and deliberate attempt to equalize the status of professionals and patients (Mclaughlin 
2009; Scourfield 2010). Involving patients in health care, or co-producing health care, has been put forward as a way to improve health care services. All too often strategies to co-produce care are rooted in professionally dominated approaches where patients are consulted only at a level where they have little opportunity to influence care. Co-production with patients with experiential expertise can be seen as an ethic way of addressing power imbalances as experts by experiences have collective experiential knowledge and the appropriate skills to collaborate as an equal partner of health care professionals.

\section{Appendix 1}

Author Definition

Health care

Borkman (1976)

Foundation for learning disabilities

Care Quality Commission (2016) http://www. cqc.org.uk/content/become-an-expert-exper ience
Experiential knowledge is truth learned from personal experience with a phenomenon rather than truth acquired by discursive reasoning, observation, or reflection on information provided by others. The two most important elements of experiential knowledge are (1) the type of information on which it is based and (2) one's attitude towards that information. * The type of information is wisdom and know-how gained from personal participation in a phenomenon instead of isolated, unorganized bits of facts and feelings upon which a person had not reflected. This wisdom and know-how tend to be concrete, specific, and commonsensical, since they are based on the individual's actual experience, which is unique, limited, and more or less representative of the experience of others who have the same problem. *The second element is the certitude that what one experiences indeed becomes knowledge. Experiential knowledge is the "truth learned from personal experience with a phenomenon", and experiential expertise refers to "competence or skill in handling or resolving a problem through the use of one's own experience',

A term used by the recovery movement to draw attention to the value of working alongside service users. A particular approach which acknowledges a person's capacity to work towards their own rehabilitation

Experts by Experience are people who have personal experience of using or caring for someone who uses health, mental health, and/or social care services that we regulate 


\begin{tabular}{l} 
Author \\
\hline Commission for Social Care Inspection (2009) \\
in Scourfield (2010)
\end{tabular}

Carer Quality Commission (2009) in Scourfield (2010)

Burda et al. (2016)

\section{Definition}

People who have chosen to become more closely involved with the organization, developing their skills, knowledge, and expertise (CSCI 2009)

An expert by experience is a person who, because of their shared experience of using services, and/ or ways of communication, visits a service with an inspector to help them get a picture of what it is like to live in or use the service. Experts by experience do not need to have experienced an identical service. What matters is that they know what it is like to need a service

Experts by experience are people who are using services now or have done so in the past, people who need services but have not been offered them, people who need services but have not been offered any that are appropriate, people living with or caring for a person who uses services

Having the experience of living with a chronic disease implies having experiential knowledge. When this experiential knowledge of patients is joined and shared, a communal body of knowledge - called experiential expertise — can arise

Experiential expertise relates to the disorder as a physical-biological and psychosocial entity and relates to social roles in various life domains, such as family, school/work, social networks, public places, and health care services. An essential aspect of experiential expertise is its transmissibility to peers and others and aimed at the benefit of peers. Experiential expertise contributes to the improvement of ways to deal with and solve restrictions resulting from the disorder and the medical regimen, with the emphasis on consequences for daily life. An important aim of transferring experiential expertise is to help people with a chronic disease increase their social integration and societal participation and hence achieve the quality of life they aspire to

Patient-specific knowledge is often implicit and concerns the lived experiences of individual patients regarding their bodies and their illnesses as well as cure and care. The first step towards experiential expertise is made when these experiences are converted into personal insights that enable a patient to cope with their individual illness and disability. When experiences are tested and shared by peers, the communal body of knowledge exceeds the boundaries of individual experiences and starts being 'experiential expertise,' which can be transferred to peers. Experiential expertise can be regarded as an intersubjective body of competence in terms of attitude, knowledge, and skills, tested and adapted continuously in daily life by the experiential experts themselves 


Author Definition

Popay and Williams (1996) in Thompson et al. (2012)

Gielen et al. (2010)

Currana et al. (2015)

de Jonge (1994)

Deegan (1993)

Mental health care
The implicit, direct knowledge, experience, and understanding that an individual has about their body, health, and illness or about health services, care, and treatment

Expertise by experience starts, as the word suggests, from a personal, specific experience related to a problem. At a later stage, that problem is converted to a personal interpretation of the problem. In other words, experiential knowledge is specific and tangible. It is about the tacit and embodied knowledge of an individual. Expertise by experience also has another dimension: it involves the ability to tackle and resolve a problem. By this, Expertise by experience transcends the individual experience. It is more about abstracted knowledge that can be enabled to help others. Expertise by experience is embedded knowledge on a collective level. It is a gradual quality - one can have less or more Expertise by experience-and it is dynamic. Expertise by experience can indeed change over time. It is transferred in self-help groups from peer to peer. Gradually, it also starts to gain ground in regular care, where it is enabled externally. [Own translation]

We use the term 'expert by experience' to refer to roles beyond the immediate experience of being a service user or carer when that expertise is deployed in other situations, for example, for contributing to student recruitment, teaching, research, policy consultation, or service improvement

The development of expertise by experience is a process. Combining individual experiences does not necessarily generate experience-based knowledge

Experience-based knowledge only arises when analyzing those experiences and when theories based on experiences from the field are generated. Expertise by experience is established through a process where individual experiences are combined and where theories based on experiences that lean on shared experiences are formulated

One can speak of expertise by experience when a patient recovered sufficiently and when he is able to cope with his problems. It also means that the patient can see his illness in a wider context. He has knowledge about his condition and knows which factors contribute to recovery. $\mathrm{He}$ also has a view on his condition and the therapies he has followed. With this knowledge, he is able to help others on their way to recovery 


\begin{tabular}{l} 
Author \\
\hline $\begin{array}{l}\text { Geestelijke gezondheidszorg Eindhoven en de } \\
\text { Kempen (2011) }\end{array}$
\end{tabular}

Boevink (2017)

\section{Definition}

Expertise by experience is a source of knowledge that is founded upon experience, upon the process of recovery and the exchange of your own personal story with the stories of others. The struggle with several complaints, psychological illness, opposition, and uncertainties about choices made are all part of this. In addition, resilience, the ability to find creative solutions and adjustments, the support of others, the new identity, and new experiences are a source of expertise by experience. Therefore, expertise by experience is not something that can be learned through education. It is the ability to apply and use all the knowledge gathered from those experiences. [Own translation]

In order to gain confidence in your own power, and to be able to develop and expand that power, experience-based knowledge is required: knowledge about what improves and what impedes one's own recovery process. In our view, recovery and empowerment lean on experience-based knowledge and expertise by experience. People who have experienced severe and long-term psychological suffering, all have a unique story. This story encompasses the meaning that people give to their problems and the strategies they develop to cope with these problems. This is the so-called personal experience-based knowledge. Together, all these individual stories form collective experience-based knowledge: knowledge about what it is like to live with psychological vulnerability and its consequences. If someone is capable of transferring this knowledge to others, in any form, we use the term expertise by experience. Expertise by experience is essential for the recovery of people diagnosed with psychological illness. At an individual level, it contributes to the empowerment of peers in their search for their own powers. At a higher level, it clears the way for the influence of clients on the improvement of medical care. [Own translation] 


Author Definition

Karbounianiss and Brettscheider (2009)

Expertise by experience is the result of a processing process and of the reflection about...

Recognition and acknowledgement are the leading principles. Although knowledge can be meaningful for one's personal life and the life of peers initially, it should also be verifiable, for instance, by evaluation research

Experience-based knowledge is the expertise by experience and knowledge:

That is used, and considered useful by experts by experience

That is based on the experts by experiences' own experience

That refers to competencies to commit knowledge in favor of a third party (e.g., phrasing emotional experiences)

That can be used in several fields and practices

But that can be applicable to a specific area and a specific context. [Own translation]

Koningin Fabiolafonds voor de Geestelijke Gezondheid (2009)

Korevaar and Droës (2008)

Plooy (2007)
Expertise by experience is the specific expertise that was constructed by learning-from-experiences: by taking your own experiences seriously, by processing them for yourself and reflecting on them and additionally by considering similar experiences of others as being serious, by listening to those experiences and assimilating them in own reflections. [Own translation]

Expertise by experience is good example of how empowerment works. It encompasses the idea of sharing own experiences with peers. Throughout this process one will gradually learn how own experiences can fit in a 'we-story' and how this can be applied to other contexts: e.g., improvement of care, policy making, or political action. [Own translation]

Expertise by experience is a skill, a profession based on specific and mature knowledge. It is embedded in comprehensive literature of experience stories of people with long-term psychological illness. It is knowledge that is supported by scientific research and that leans on the experiences and the development of the clientmovement in the 30s. This knowledge refers to the recovery of psychological illness and the support of people with psychological illness. Experiential knowledge is the integration of individual experiences into a commonly shared story. That is expert by experience. When you have the ability to transfer this knowledge in an efficient way, and when you put it at stake for the improvement of the position of psychiatric patients, then you develop something that we could call expertise by experience. [Own translation] 
Author

Posthouwer and Timmer (2013)

Ruis et al. (2012)

van Erp et al. (2011)

Social Work (poverty)

Casman et al. (2010)

Spiesschaert et al. (2009)

\section{Definition}

Expertise by experience is the professional dedication and transfer of knowledge gathered by analysis of and reflection on one's own experiences and experiences of peers, completed with knowledge from other sources such as literature, presentations, and media. [Own translation]

One can speak of expertise by experience when people offer emotional, social, or practical help and engage personal experiences to help people with similar experiences (peers). [Own translation]

Expertise by experience is the expertise in supporting others to develop your own experiential knowledge and to support the recovery process. At the same time, it is the expertise in the field of more general experience knowledge and the enabling of it in care and in the emancipation and the battle against stigmatization. [Own translation]

This experience is:

Assimilated: the capacity of experts by experience to carry out their missions effectively requires, initially, that they have assimilated the experiences acquired all along their own life path spent in poverty

Supplemented by specific training: during the first three years of their engagement, these experts by experience follow a part-time training course, which is intended to prepare them to take up their activities within the federal public services

Connected to wider horizons acquired by the exchange and the expertise of others' experiences: these three years of training are an opportunity for the experts by experience of similar mind to be in contact with each other on a regular basis and to exchange thoughts on their respective paths. Moreover, the training process aims at maximizing the dynamics of exchange and expression

Gradually enriched by professional experience: finally, expertise acquired through real-life experiences continues to be refined and to become enriched by doing the professional work itself

Trained experts by experience in poverty and social exclusion are persons who have experienced poverty since birth. They have processed and expanded their experience to broader poverty experience, and through training they were handed attitudes, skills, and methods to practice and apply the broadened poverty experience in a well-grounded way in all fields of poverty prevention. [Own translation] 


\begin{tabular}{ll}
\hline Author & Definition \\
\hline Spiesschaert (2005) & $\begin{array}{l}\text { Trained experts by experience in poverty and } \\
\text { social exclusion, persons who have experienced } \\
\text { poverty, who have coped with and extended } \\
\text { this experience and who, through training, have } \\
\text { acquired attitudes, skills, and methods to apply } \\
\text { this extended poverty experience professionally in } \\
\text { one or several areas of the fight against poverty. In } \\
\text { other words, they have received the opportunity } \\
\text { through training to start or continue their coping } \\
\text { process, to extend their experiences with that of } \\
\text { others and to develop attitudes, skills, and meth- } \\
\text { ods which are important in the field of practice. } \\
\text { However, the official designation of the training, } \\
\text { as it is recognized by the department of educa- } \\
\text { tion, differs from the term used in the poverty } \\
\text { decree. The latter refers to expert by experience in } \\
\text { poverty, while within the department of education, } \\
\text { the training is known as training for "experience } \\
\text { expert in poverty and social exclusion" }\end{array}$ \\
\end{tabular}

\section{Appendix 2}

\begin{tabular}{lllll}
\hline & Discipline & Gender & Sector & Country \\
\hline Respondent 1 & Expert by experience & $\mathrm{f}$ & Medical health & Belgium \\
Respondent 2 & Expert by experience & $\mathrm{f}$ & Medical health & Belgium \\
Respondent 3 & Expert by experience & $\mathrm{f}$ & Medical health & Belgium \\
Respondent 4 & Expert by experience & $\mathrm{m}$ & Medical health & Belgium \\
Respondent 5 & Professional & $\mathrm{f}$ & Medical health & Belgium \\
Respondent 6 & Expert by experience & $\mathrm{m}$ & Medical health & Netherlands \\
Respondent 7 & Expert by experience & $\mathrm{m}$ & Medical health & Netherlands \\
Respondent 8 & Expert by experience & $\mathrm{m}$ & Mental health & Belgium \\
Respondent 7 & Expert by experience & $\mathrm{m}$ & Mental health & Belgium \\
Respondent 9 & Expert by experience & $\mathrm{f}$ & Mental health & Belgium \\
Respondent 10 & Expert by experience & $\mathrm{f}$ & Mental health & Belgium \\
Respondent 11 & Professional & $\mathrm{m}$ & Mental health & Belgium \\
Respondent 12 & Professional & $\mathrm{f}$ & Mental health & Belgium \\
Respondent 13 & Researcher & $\mathrm{m}$ & Mental health & Belgium \\
Respondent 14 & Researcher & $\mathrm{m}$ & Mental health & Netherlands \\
Respondent 15 & Expert by experience & $\mathrm{m}$ & Social work & Belgium \\
Respondent 16 & Professional and researcher & $\mathrm{m}$ & Social work & Belgium \\
Respondent 17 & Professional & $\mathrm{m}$ & Social work & Belgium \\
\hline
\end{tabular}




\section{References}

Abel, K., and C. Browner. 1998. Selective compliance with biomedical authority and the uses of experiential knowledge. In Pragmatic women and body politics, ed. M. Lock, and P. Kaufert. Cambridge: Cambridge University Press.

Batalden, M., et al. 2017. Coproduction of healthcare service. BMC Quality \& Safety. https://doi. org/10.1136/bmjqs-2015-004315.

Blume, S. 2017. In search of experiential knowledge. Innovation: The European Journal of Social Science Research 30 (1): 91-103. https://doi.org/10.1080/13511610.2016.1210505.

Boevink, W. 2006. Stories of recovery. Working together towards experiential knowledge in mental health care. Utrecht: Trimbos-instituut.

Boevink, W. 2012. HEE: towards recovery, empowerment and experiential expertise of users of psychiatric services. In Empowerment, lifelong learning and recovery in mental health: towards a new paradigm, ed. P. Rian, S. Ramon, and T. Greacen, 36-50. New York: Palgrave.

Boevink, W. 2017. Hee! Over Herstel, Empowerment en Ervaringsdeskundigheid in de psychiatrie. Utrecht: Trimbos Instituut.

Boevink, W., et al. 2016. 'A user-developed, user run recovery programme for people with severe mental illness: A randomised control trial'. Psychosis 2439: 1-14. https://doi.org/10.1080/17522 439.2016.1172335.

Boivin, A. 2014. What are the key ingredients for effective public involvement in health care improvement and policy decisions? A randomized trial process evaluation. The Milbank quarterly 92 (2): 319-350. https://doi.org/10.1111/1468-0009.12060.

Borkman, T. 1976. Experiential Knowledge: A analysis of self-help groups. Social Service Review 50 (3): 445-456.

Bovenberg, F., G. Wilrycx, and G. Francken. 2011. Inzetten van ervaringsdeskundigheid [The enablement of expertise by experience]. Sociale Psychiatrie 29: 21-28.

Burda, M.H.F., et al. 2012. Harvesting experiential expertise to support safe driving for people with diabetes mellitus: A qualitative study evaluated by peers in a survey. Patient 5 (4): 251-264. https://doi. org/10.2165/11631620-000000000-00000.

Burda, M.H.F., et al. 2016. Collecting and validating experiential expertise is doable but poses methodological challenges. Journal of Clinical Epidemiology 72: 10-15. https://doi.org/10.1016/j.jclin epi.2015.10.021.

Caron-Flinterman, J.F., J.E.W. Broerse, and J.F.G. Bunders. 2005. 'The experiential knowledge of patients: A new resource for biomedical research?'. Social Science \& Medicine (1982) 60 (11): 2575-2584. https://doi.org/10.1016/j.socscimed.2004.11.023.

Casman, M.-T., et al. 2010. Experts by experience in poverty and in social exclusion. Antwerp-Apeldoorn: Garant.

Castro, E.M., T. Van Regenmortel, K. Vanhaecht, W. Sermeus, and A. Van Hecke. 2016. Patient empowerment, patient participation and patient-centeredness in hospital care: A concept analysis based on a literature review. Patient Education and Counseling 99 (12): 1923-1939.

Castro, E.M., et al. 2017. 'Co-design for implementing patient participation in hospital services: A discussion paper. Patient Education and Counseling. https://doi.org/10.1016/j.pec.2018.03.019.

Castro, E.M.Van, T. Regenmortel, C. Van Wanseele, W. Sermeus, and K. Vanhaecht. 2018. Participation and healthcare: a survey investigating current and desired levels of collaboration between patient organizations and hospitals. Journal of Social Intervention: Theory and Practice 27 (4): 4-28.

Civan, A., et al. 2009. 'Locating patient expertise in everyday life'. GROUP ACM SIGCHI Int Conf Support Group Work., pp. 291-300. https://doi.org/10.3816/clm.2009.n.003.novel.

Crawford, M.J., et al. 2002. 'Systematic review of involving patients in the planning and development of health care. BMJ Clinical Research 325: 1263.

Currana, T., R. Sayers, and B. Percy-Smith. 2015. Leadership as experts by experience in professional education. Procedia - Social and Behavioral Sciences 186: 624-629.

de Jonge, M. 1994. Beroep cliëntdeskundige. Een nieuwe ster aan het firmament van de gezondheidszorg. Medisch Contact 49: 1627-1628.

Deegan, P. 1993. Recovering our sense of value after being labelled mentally ill. Journal of Psychosocial Nursing 31 (4): 7-11.

Dreyfus, S., and H. Dreyfus. 1980. A five-stage model of the mental activitities involved in directed skill acquisition. Berkeley. 
Erp, N. D. Van Boertien, S. Van Rooijen. 2015. 'Basiscurriculum Ervaringsdeskundigheid. Bouwstenen voor onderwijs en opleidingen voor ervaringsdeskundigen [Basic Curriculum experiential expertise Foundation for education and training for experience experts].', p. 146. http://www.kenniscentrumph renos.n1/wp-content/uploads/2015/04/AF1373-basiscurriculum-ervaringsdeskundigheid_web.pdf.

Frampton, P. et al. 2008. Patient-centered care improvement guide. Derby. http://planetree.org/wp-conte nt/uploads/2015/03/Patient-Centered-Care-Improvement-Guide-10.10.08.pdf. Accessed 22 Nov 2015.

Gielen, P., J. Godemont, K. Matthijs, and A. Vandermeulen. 2010. Zelfhulpgroepen. Samenwerken aan welzijn en gezondheid. Leuven: Lannoo Campus.

Goertz, Gary. 2006. Social science concepts: A user's guide. Princeton and Oxford: Princeton University Press.

Greenhalgh, T. 2005. Effectiveness and efficiency of search methods in systematic reviews of complex evidence: Audit of primary sources. BMJ 331 (7524): 1064-1065. https://doi.org/10.1136/ bmj.38636.593461.68.

Karbouniaris, S, and E. Brettschneider, E. 2008. Inzet en waarde van ervaringsdeskundigheid in de GGZ [Enablement and value of expertise by experience in mental health care]. Utrecht.

Knooren, J. 2010. Training psychiatric clients to become experts by experience. European Journal of Social Education 16: 201-208.

Korevaar, L., and J. Droës. 2011. Handboek rehabilitatie voor zorg en welzijn Handbook rehabilitation for care and well-being]. Bussum: Coutinho.

Lam, A. 2000. 'Tacit knowledge, organizational learning and societal institutions: An integrated framework. Organization Studies 21 (3): 487-513. https://doi.org/10.1177/0170840600213001.

Malfait, S., K. Eeckloo, and A. Van Hecke. 2017. The influence of nurses' demographics on patient participation in hospitals: A cross-sectional study. Worldviews on Evidence-Based Nursing 14 (6): $455-462$.

Mclaughlin, H. 2009. 'What' s in a name : "Client", "patient”, “customer”, “consumer", "expert by experience", "service user"-what' s next ? The British Journal of Social Work 39 (6): 1101-11147.

Miaskiewicz, T., and K.A. Kozar. 2011. Personas and user-centered design: how can personas benefit product design processes. Design Studies 32: 417-430.

Mockford, C., et al. 2012. 'The impact of patient and public involvement on UK NHS health care: A systematic review. International Journal for Quality in Health Care : Journal of the International Society for Quality in Health Care/ISQua 24 (1): 28-38. https://doi.org/10.1093/intqhc/mzr066.

Nickel, S., A. Trojan, and C. Kofahl. 2016. Involving self-help groups in health-care institutions: the patients' contribution to and their view of "self-help friendliness" as an approach to implement quality criteria of sustainable co-operation. Health Expectations. https://doi.org/10.1111/hex.12455.

Plooy, A. 2007. Ervaringsdeskundigen in de hulpverlening-bruggenbouwers of bondgenoten! [Experience Experts in counseling_-bridge builders or allies!]. Tijdschrift voor Rehabilitatie 16 (2): 14-21.

Polit, D., and C. Beck. 2012. Nursing Research: Generating and assessing evidence for nursing practice, vol. 9. Philadelphia: Wolters Kluwer/Lippincott/Williams \& Wilkins Health.

Posthouwer, M., and H. Timmer. 2013. Een ervaring rijker [A new experience]. Amsterdam: SWP.

Repper, J., and T. Carter. 2011. A review of the literature on peer support in mental health services. Journal of Mental Health 20 (4): 392-411. https://doi.org/10.3109/09638237.2011.583947.

Rietbergen, C., E. Mentink, and L. Verkuyl. 1998. Inzet van ervaringsdeskundigheid bij de (re)integratie van arbeidsgehandicapten [Deployment of experiential expertise in the (re) integration of disabled people]. Utrecht.

Rodgers, B., and K. Knafl. 2000. Concept development in nursing: foundations, technqiues, and applications. Amsterdam: Elsevier.

Roets, G., et al. 2012. Pawns or pioneers? the logic of user participation in anti-poverty policy-making in public policy units in belgium. Social Policy and Administration 46 (7): 807-822. https://doi.org/10 .1111/j.1467-9515.2012.00847.x.

Ruis, J., D. Polhuis, and I. de Hoop. 2012. Ervaring is de beste leermeester. De meerwaarde en positie van ervaringsdeskundigen. Vakblad Sociale Psychiatrie 31: 43-46.

Schwartz-Barcott, D., and S. Kim. 2000. An expansion and elaboration of the hybrid model of concept development. In Concept development in nursing: foundations, techniques, and applications, ed. B.L. Rodgers, and K.A. Knafl. Philadelphia: Saunders.

Scourfield, P. 2010. A critical reflection on the involvement of "experts by experience" in inspections. British Journal of Social Work 40 (6): 1890-1907. https://doi.org/10.1093/bjsw/bcp119. 
Sharma, A.E., et al. 2017. 'The impact of patient advisors on healthcare outcomes: A systematic review. BMC Health Services Research 17 (1): 7. https://doi.org/10.1186/s12913-017-2630-4.

Solbjør, M., and A. Steinsbekk. 2011. User involvement in hospital wards: Professionals negotiating user knowledge. A qualitative study. Patient Education and Counseling 85 (2): 144-149. https://doi. org/10.1016/j.pec.2011.02.009.

Spiesschaert, F., D. Trimbos, and M. Vangertruyden. 2009. De methodiek Ervaringsdeskundige in Armoede en Sociale Uitsluiting. Kennis uit het werkveld. Berchem: De Link vzw.

Tambuyzer, E., G. Pieters, and C. Van Audenhove. 2014. Patient involvement in mental health care: One size does not fit all. Health Expectations 17 (1): 138-150. https://doi.org/10.111 1/j.1369-7625.2011.00743.x.

Thompson, J., et al. 2012. Credibility and the "professionalized" lay expert: Reflections on the dilemmas and opportunities of public involvement in health research. Health: An Interdisciplinary Journal for the Social Study of Health Illness and Medicine 16 (6): 602-618. https://doi.org/10.1177/13634 59312441008.

Timmer, H., and A. Plooy. 2009. Weten over leven, ervaringskennis van mensen met langdurende psychische aandoeningen [Knowing about life, experience knowledge of people with long-term psychiatric disorders ]. Amsterdam: SWP.

Tritter, J.Q. 2009. 'Revolution or evolution: the challenges of conceptualizing patient and public involvement in a consumerist world. Health Expectations : An International Journal of Public Participation in Health Care and Health Policy 12 (3): 275-287. https://doi.org/10.1111/j.1369-7625.2009.00564 .x.

Utschakowski, J. (2017) Foundations and consequences of experiential knowledge.

Vandenbempt, K., and B. Demeyer. 2003. Beroepsprofiel. Ervaringsdeskundige in de armoede en sociale uitsluiting. Leuven: Garant Publishers.

van Bakel, M. et al. 2013. Ervaringsdeskundigheid Beroepscompentieprofiel [Experiential Expertise Competency Profile]. Utrecht/Amersfoort. www.ggznederland.nl.

van Erp, N., M. van Wezep, A. Meijer, H. Henkens, and S. van Rooijen. 2011. Werk en opleiding voor ervaringsdeskundigen: Transitie-experiment Eindhoven. Utrecht: Trimbosinstituut.

Van Erp, N., et al. (no date) Werk en opleiding voor ervaringsdeskundigen [Work and training for experience experts]. Eindhoven.

van Haaster, H., and Y. Koster-Dreese. 2005. Ervaren en weten [Experience and Knowledge]. Utrecht: Jan Van Arkel.

van Haaster, H. et al. 2013. Kaderdocument ervaringsdeskundigheid [Framework Experiential expertise]. Utrecht.

Van Regenmortel, T. 2009. Koningin Fabiolafonds voor de Geestelijke Gezondheid, pp. 1-8.

Van Regenmortel, T. 2011. Ervaringsdeskundigheid in de geestelijke gezondheidszorg met betrekking tot werk. [Experiential expertise in mental health related to work]. Welzijnsgids (Gezondheidszorg, Geestelijke gezondheidszorg) 29: 1-22.

Verbrugge, C.J.J.M., and P.J.C.M. Embregts. 2013. Een opleiding ervaringsdeskundigheid voor mensen met een verstandelijke beperking [Training experiential expertise for people with intellectual disabilities]. Tilburg.

World Health Organisation. 2015. WHO global strategy on people-centred and integrated health services. Geneva: World Health Organisation. http://www.who.int/servicedeliverysafety/areas/people-centr ed-care/global-strategy/en/. 